\title{
Effect of Antimony Additions on Corrosion and Mechanical Properties of Sn-Bi Eutectic Lead-Free Solder Alloy
}

\author{
Alberto Torres, Luis Hernández, Octavio Domínguez* \\ Instituto de Metalurgia-UASLP, San Luis Potosí, México. \\ Email: ${ }^{*}$ nanochemmex@yahoo.com
}

Received February $29^{\text {th }}, 2012$; revised March $28^{\text {th }}, 2012$; accepted April $27^{\text {th }}, 2012$

\begin{abstract}
The goal of the present work is to investigate the effects of the addition of $\mathrm{Sb}(0,3$ and $6 \mathrm{wt} \%)$ on structure, melting, corrosion and mechanical properties of $\mathrm{Sn}-\mathrm{Bi}$ eutectic solder alloys. The mechanical properties of the bulk $\mathrm{Sn}-\mathrm{Bi}-\mathrm{Sb}$ solders were higher as the amount of antimony increases, making compressive strength augment from $65 \mathrm{MPa}$ to 100 $\mathrm{MPa}$ when $6 \mathrm{wt} \% \mathrm{Sb}$ was incorporated to the Sn-Bi eutectic alloy. The three alloys presented a melting temperature that is smaller to the one exhibited by the eutectic alloy $\mathrm{Sn}-38 \mathrm{~Pb}\left(\mathrm{~T}_{\mathrm{m}}=183^{\circ} \mathrm{C}\right)$. According to the electrochemical results, the addition of higher contents of $\mathrm{Sb}$ to the $\mathrm{Sn}-\mathrm{Bi}$ eutectic alloy had a positive effect: it ennobled the $\mathrm{E}_{\text {corr }}$ values.
\end{abstract}

Keywords: Lead Free Solder Alloys; Sn-Bi-Sb; Mechanical Properties; Corrosion Properties

\section{Introduction}

Due to the toxicity and harmful environmental effect of $\mathrm{Pb}$ present in tin solders, legislation trend to reduce or eliminate the utilization of lead from a wide variety of uses. There are many different metals and metal alloys that can be used as solders and a set of binary alloys have been chosen as candidates for lead-free solders: Sn-Bi, $\mathrm{Sn}-\mathrm{Ag}, \mathrm{Sn}-\mathrm{Zn}, \mathrm{Sn}-\mathrm{Cu}$ and Sn-Sb. Among the ternary compositions, the $\mathrm{Sn}-\mathrm{Bi}-\mathrm{Zn}$ one was used in making printing wiring boards [1], however all of these eutectic compositions have a melting temperature above $200^{\circ} \mathrm{C}$. Sn-Zn eutectic has a lower melting temperature of $199^{\circ} \mathrm{C}$, but its corrosion behavior and poor wetting ability renders it useless [2]. Among the commercial Pb-free alloys, Sn-58 $\mathrm{wt} \% \mathrm{Bi}$ eutectic alloy may be a favorable alloy specially for electronics and telecommunications. In fact, this alloy, which has the eutectic temperature of $139^{\circ} \mathrm{C}$, has a higher ultimate tensile stress and shear strength than $\mathrm{Sn}-\mathrm{Pb}$ eutectic $[2,3]$. Bismuth has also been used as the alloying element in ternary Sn-Zn-Bi [4] Sn-Ag-Bi [5,6] and Sn-Bi$\mathrm{Cu}$ [7] systems to provide suitable substitutes for $\mathrm{Sn}-\mathrm{Pb}$ solder alloys.

In an effort to develop lead-free solders, most research up to now focused on melting points and physical strengths of alloys, and there has been little consideration of the corrosion properties of base alloys for lead-free

${ }^{*}$ Corresponding author. solders [8-10]. Moreover, the properties of these $\mathrm{Sn}-\mathrm{Bi}-\mathrm{Sb}$ lead-free alloys in corrosive environments have not been reported, and most of the fluxes are chloride or fluoride base compounds. As a result, most of the corrosion associated with soldered joints is due to the use of improper or insufficient cleaning methods to remove the fluxes [11]. Consequently, the objective of this preliminary study is to investigate the effects of the addition of Sb on structure, melting, corrosion and mechanical properties of SnBi eutectic solder alloys.

\section{Experimental Procedure}

\subsection{Materials and Processing}

The materials used were three $\mathrm{Sn}-58 \% \mathrm{Bi}$ alloys, containing 0, 3 and $6 \mathrm{wt} \% \mathrm{Sb}$. The samples were prepared from high purity $(99.99 \%)$ tin, bismuth and antimony metals, melted in an electrical furnace under inert argon atmosphere and cast into slabs in alumina crucibles. The chemical composition of the produced alloys was determined by Atomic Absorption Spectrometry (Table 1).

Table 1. Chemical composition of manufactured alloys (wt\%).

\begin{tabular}{ccc}
\hline SYSTEM & Nominal & Experimental \\
\hline Sn58Bi0Sb & $58 \mathrm{Bi}-42 \mathrm{Sn}$ & $57.45 \mathrm{Bi}-42.55 \mathrm{Sn}$ \\
$\mathrm{Sn} 58 \mathrm{Bi} 3 \mathrm{Sb}$ & $56.25 \mathrm{Bi}-40.75 \mathrm{Sn}-3 \mathrm{Sb}$ & $56.18 \mathrm{Bi}-40.77 \mathrm{Sn}-3.05 \mathrm{Sb}$ \\
$\mathrm{SnBi}-6 \mathrm{Sb}$ & $54.52 \mathrm{Bi}-39.48 \mathrm{Sn}-6 \mathrm{Sb}$ & $53.23 \mathrm{Bi}-41.02 \mathrm{Sn}-5.75 \mathrm{Sb}$ \\
\hline
\end{tabular}




\subsection{Thermal, Structural, Mechanical and Electrochemical Characterization}

The thermal behavior of the alloys was investigated using a Perkin-Elmer differential scanning calorimeter (DSC). The specimens with an approximate weight of $50 \mathrm{mg}$ were heated to $300^{\circ} \mathrm{C}$, under inert argon atmosphere, with a constant rate of $10^{\circ} \mathrm{C} / \mathrm{min}$. The structure of the alloys was examined by X-ray diffraction (XRD) using a Rigaku diffractometer with $\mathrm{CuK}$ radiation $(\lambda=1.54056$ A). A scanning electron microscope (SEM) model Philips XL-30 was used for microstructural analysis and energy dispersive X-ray spectroscopy (EDX) was performed in the SEM to analyze the chemical composition of the alloys. The compressive tests were conducted at room temperature using a Shimadzu AG-I universal testing machine with a constant cross-head speed of $0.5 \mathrm{~mm} / \mathrm{min}$. Vickers hardness $(\mathrm{VH})$ was measured using a Vickers microhardness tester.

The specimens were polished with grade 600 and 1000 carborundum papers, rinsed with distilled water and acetone and dried with hot air, previously to the electrochemical tests. The open circuit corrosion potential $\left(\mathrm{E}_{\text {corr }}\right)$ of all specimens was recorded before the potentiodynamic polarization measurements using a saturated calomel electrode (SCE) as reference. It was used a cell for flat samples, with a contact area of $1 \mathrm{~cm}^{2}$ between working electrode and electrolyte (a $3 \% \mathrm{NaCl}$ solution). The cell contained a great superficial area platinum electrode as the counter electrode, and the reference electrode already mentioned. Potentiodynamic polarization measurements were conducted with a scan rate of $10 \mathrm{mV} / \mathrm{min}$. Cathodic potentiodynamic scans were carried out first, starting at the $\mathrm{E}_{\text {corr }}$ value to around $-1200 \mathrm{mV}_{\text {sce. }}$. Anodic scans were done, after a return to steady-state conditions, from the $\mathrm{E}_{\text {corr }}$ value to around $500 \mathrm{mV}_{\text {sce }}$. All electrochemical measurements were carried out at room temperature and with no de-aeration of the electrolyte.

\section{Results and Discussion}

\subsection{Phases and Microstructure}

Figure 1 shows the corresponding $\mathrm{Sn}-\mathrm{Bi}, \mathrm{Bi}-\mathrm{Sb}$ and $\mathrm{Sn}-\mathrm{Sb}$ binary phase diagrams. The Sn-Bi system displays a eutectic reaction with 43 atomic $\%$ of bismuth ( $58 \mathrm{wt} \%)$ at a temperature of $139^{\circ} \mathrm{C}$. In contrast, the Bi-Sb system freeze to form a continuous series of solid solutions, contrary to the $\mathrm{Sn}-\mathrm{Sb}$ system where the tin rich zone exhibits a peritectic reaction and limited solid solution of $\mathrm{Sb}$.

Figure 2 shows the X-ray diffraction pattern of the ascast $\mathrm{Sn}-58 \% \mathrm{Bi}$ alloy showing the only presence of $\beta$-Sn and $\mathrm{Bi}$, with no other compounds. SEM images of the as cast eutectic Sn-58 wt\% Bi alloy, obtained under conventional cooling rates, produced a fine lamellar struc-

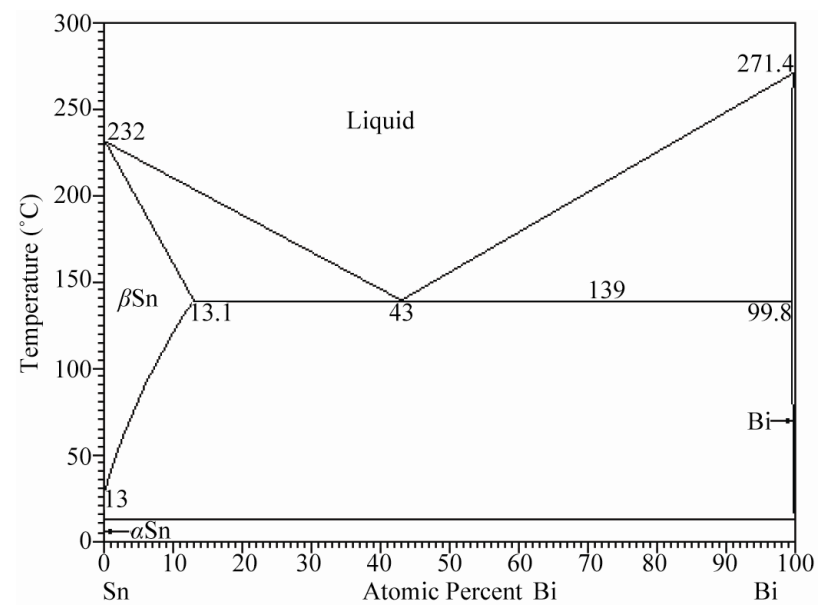

(a)

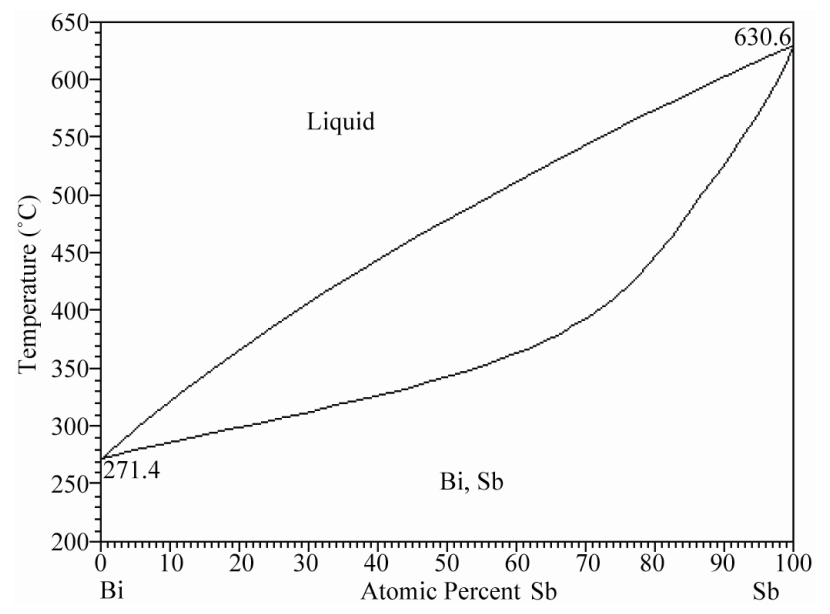

(b)



(c)

Figure 1. (a) Binary Sn-Bi phase diagram presenting the eutectic reaction; (b) Bi-Sb phase diagram exhibiting complete solid solubility; (c) Binary Sb-Sn phase diagram presenting the peritectic reaction [12].

ture.

Eutectic alloys composed of a metallic phase and a 


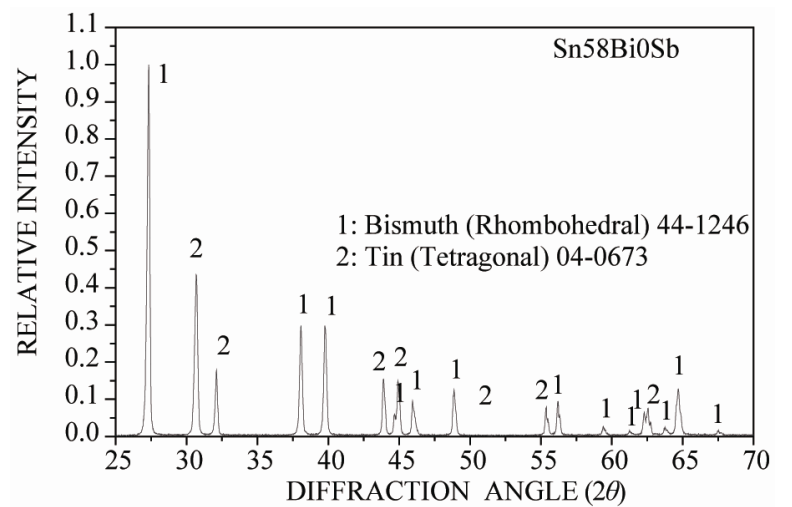

(a)

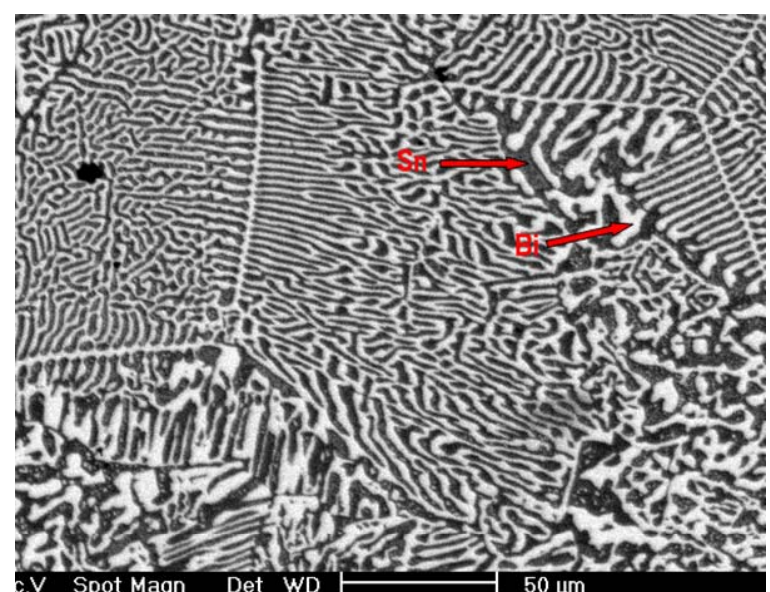

(b)

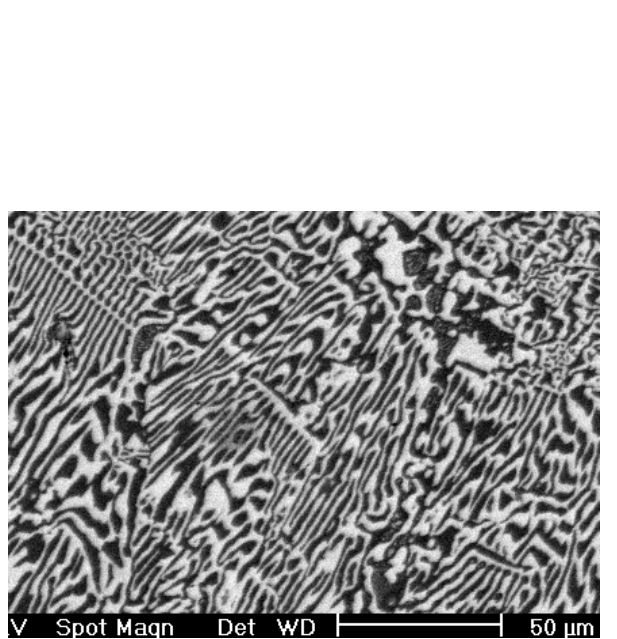

(c)


(d)

Figure 2. (a) XRD pattern obtained from the Sn-58\% Bi alloy; (b) Low magnification image obtained by SEM; (c) High magnification image indicating an interface spacing of $2.5 \mu \mathrm{m}$; (d) EDX chemical analysis of the same alloy.

semiconductor phase generally have a type II (complex regular) or type III (irregular) structure [13,14]. In the complex regular microstructure one observes two types of regions, one zones of a repeating regular pattern and other zones of random orientation as those observed on Figure 2(b). Besides, from image on Figure 2(c) obtained at higher magnification of the Sn-58 wt \% Bi alloy, a mean interface spacing of $2.5 \mu \mathrm{m}$ was measured. EDX analysis carried out on this sample indicated that the white planar phase was made of bismuth while the black phase corresponded to pure tin (Figure 2(d)), therefore corroborating the SEM images.

On the other hand, Figure 3(a) shows the X-ray diffraction pattern of the $\mathrm{Sn}-58 \mathrm{wt} \% \mathrm{Bi}-3 \mathrm{wt} \% \mathrm{Sb}$ alloy, indicating the presence of pure $\beta-\mathrm{Sn}, \mathrm{Bi}$ and the occurrence of the intermetallic compound $\mathrm{SbSn}$, in agreement to the $\mathrm{Sb}-\mathrm{Sn}$ equilibrium diagram shown in Figure 1(c). As before, SEM images of the solidified eutectic Sn-58 $\mathrm{wt} \% \mathrm{Bi}-3 \mathrm{wt} \% \mathrm{Sb}$ alloy obtained with the same casting cooling rates are shown in Figure 3. In this case, the resulting microstructure slightly differs from the first one, resulting in smaller zones of lamellar structure together with random oriented regions and coarse globular $\beta$-Sn rich phase (Figure 3(b)). In the present case, at higher magnification a mean interface secondary eutectic spacing of $1.5 \mu \mathrm{m}$ was measured in the lamellar regions (Figure 3(c)). EDX analysis carried out on sample Sn-58 wt $\%$ Bi-3 wt $\%$ Sb indicated once again that the white planar phase was only bismuth while the black zone corresponded to the $\beta$-Sn rich phase. From EDX analysis carried out on Figure 3(d) at high magnification in the globular phase with high content of $\beta$-Sn, it was not possible to detect the presence of $\mathrm{Sb}$ inside the sub-microstructure observed in these regions.

Augmenting the addition of antimony, Figure 4 shows the X-ray diffraction pattern of the Sn-58 wt $\%$ Bi- $6 \mathrm{wt} \%$ $\mathrm{Sb}$ alloy, indicating the presence of pure $\beta$-Sn, Bi and the intermetallic compound SbSn. SEM images of the solidi- 




(a)

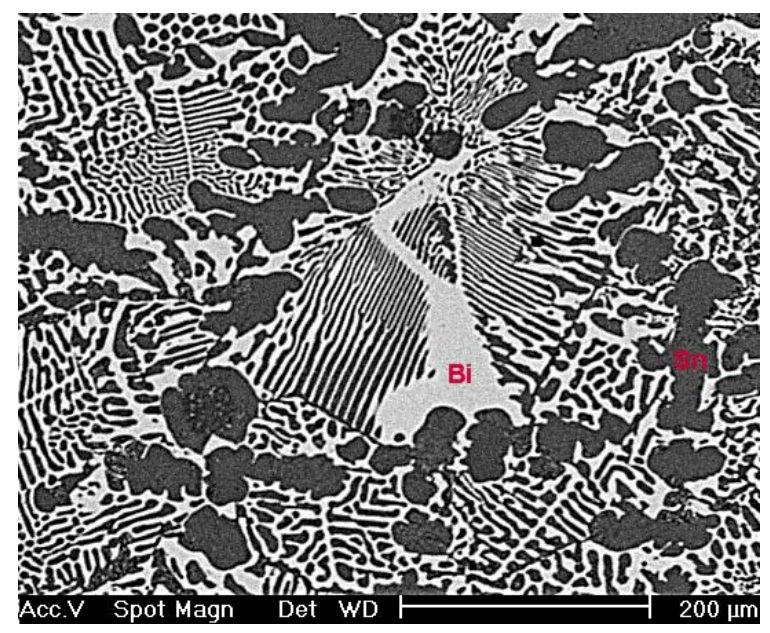

(b)

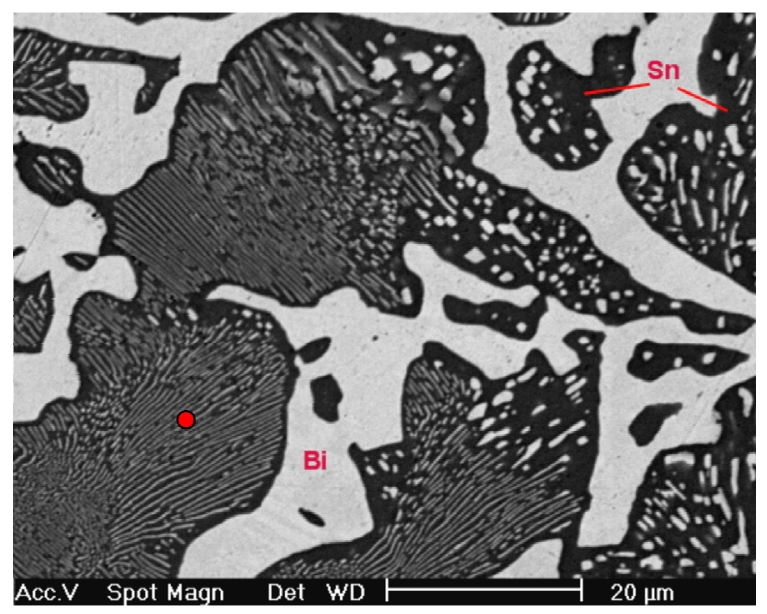

(c)



(d)

Figure 3. (a) XRD pattern obtained from the Sn-58\% Bi-3\% Sb alloy; (b) Low magnification image obtained by SEM from Sn-58\% Bi-3\% Sb alloy; (c) High magnification SEM image of the same alloy; (d) EDX chemical analysis of selected red zone.

fied eutectic $\mathrm{Sn}-58 \mathrm{wt} \% \mathrm{Bi}-6 \mathrm{wt} \% \mathrm{Sb}$ alloy processed in the same way as before, suggested that the resulting microstructure in this case was noticeably different from the other two alloys, resulting in random oriented regions and $\beta$-Sn rich dendritic phase (Figures 4(b) and (c)), so in the present case there are no eutectic lamellar regions. A planar eutectic solid/liquid interface can become unstable just as in the case of a single-phase interface. There are different ways in which instability can develop, and a reported trend corresponds to the presence of a third element that destabilizes the morphology as a whole because a long-range diffusion boundary is established ahead of the composite solid/liquid interface $[15,16]$. Therefore, the eutectic alloy composed with $6 \mathrm{wt} \%$ of $\mathrm{Sb}$ has almost changed to type III (irregular) structure. Hence, the higher concentration of the third element induces the instability of just one phase, leading to the appearance of dendrites in the solid/liquid interface.
EDX analysis carried out on sample Sn-58 wt\% Bi-6 $\mathrm{wt} \% \mathrm{Sb}$ indicated once again that the white planar phase was only bismuth while the black zone corresponded to the $\beta$-Sn rich phase. From EDX analysis carried out on Figure 4(d) at elevated magnification, it was not possible to detect the presence of $\mathrm{Sb}$ inside the observed microstructure. Probably the reason why there is always a lack of signal associated to antimony could be associated to the EDX spectrometric technique. In general, the EDX energy resolution of the equipment is about $230 \mathrm{eV}$ and the difference in $\mathrm{L}_{\alpha}$ electron binding energy transition between $\mathrm{Sn}$ and $\mathrm{Sb}$ correspond to approximately $205 \mathrm{eV}$.

\subsection{Thermal, Mechanical and Electrochemical Properties}

Figure 5 shows the thermodiagrams obtained by DSC of the manufactured $\mathrm{Sn}-\mathrm{Bi}-\mathrm{Sb}$ alloys. It is important to note that the gap between $T_{s}$ and $T_{L}$ temperatures increases 


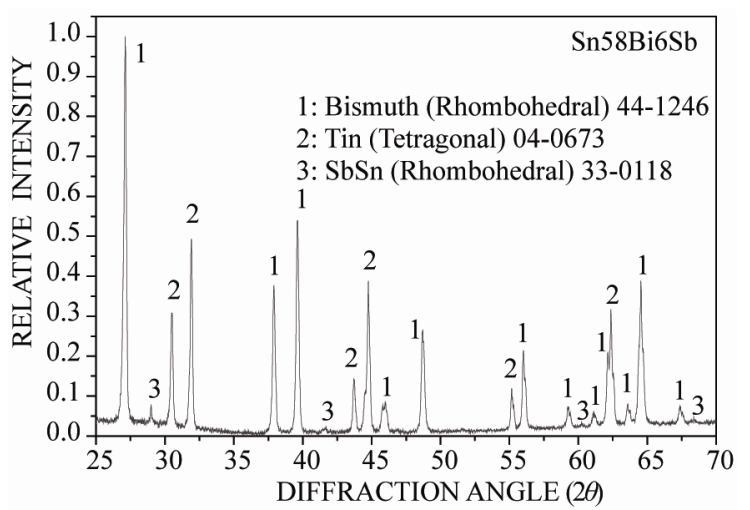

(a)



(b)

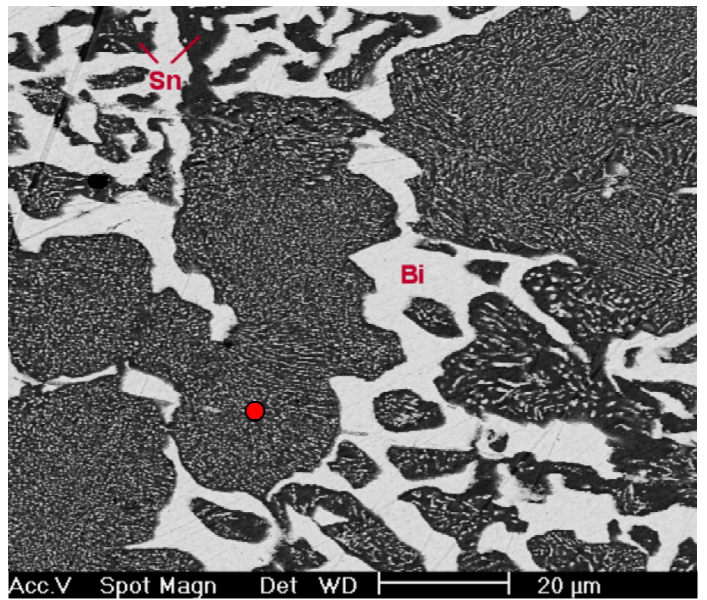

(c)

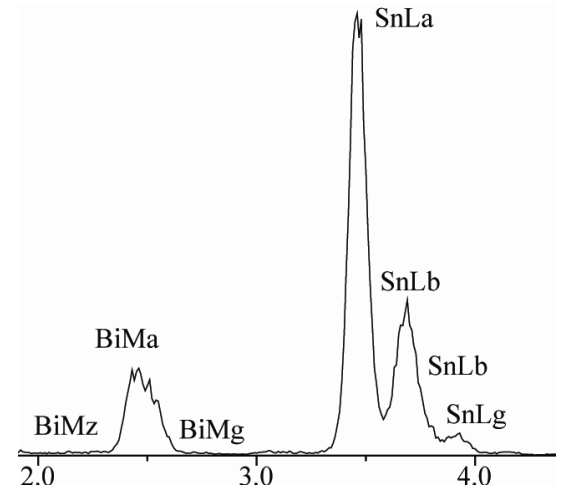

(d)

Figure 4. (a) XRD pattern obtained from the Sn-58\% Bi-6\% Sb alloy; (b) Image obtained by SEM from same alloy; (c) High magnification image; (d) EDX chemical analysis of the selected red zone.

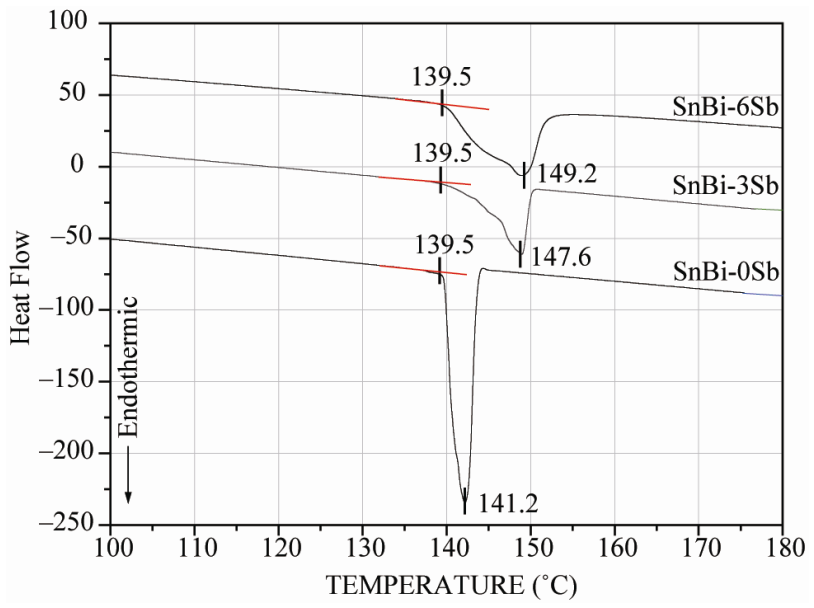

Figure 5. Thermodiagram of the as-cast manufactured solder alloys carried out in DSC at constant heating rate of $10^{\circ} \mathrm{C} / \mathrm{min}$.

with the additions of antimony into $\mathrm{Sn}-\mathrm{Bi}-\mathrm{Sb}$ solders. It is highly preferred that the difference between solidus and liquidus temperatures of solder alloys could be reduced in order to avoid liquation during soldering [17].

For an alloy with different solidus and liquidus temperatures, the composition of the melt will gradually change as the temperature increases from the solidus to liquidus. If the portion that melts first is allowed to flow out, the remaining solid may not melt and may remain behind as a residue, which is called liquation. Alloys with narrow melting ranges do not tend to liquation, but an alloy with a wide melting range needs rapid heating cycles to minimize phase separation during soldering. It is clear that both (3 and $6 \mathrm{wt} \% \mathrm{Sb}$ ) additions into the Sn-Bi eutectic alloy are not still far away from the binary eutectic composition as shown in Figure 5. Therefore, phase separation will not become a potential problem for these solder alloys because $T_{L}-T_{S}<10^{\circ} \mathrm{C}$. In addition, the three alloys present a melting temperature that is smaller to the one exhibited by the eutectic alloy $\mathrm{Sn}-38 \mathrm{~Pb}$ $\left(\mathrm{T}_{\mathrm{m}}=183^{\circ} \mathrm{C}\right)$.

Concerning the mechanical behavior of the present 
solder alloys, the homogeneous molten solder was poured into a $10 \mathrm{~mm}$ diameter steel tube and then cooled in the air. The rod was then machined to compressive specimens of $5 \mathrm{~mm}$ diameter. Specimens were not annealed to evaluate the solders. Compressive tests were carried out on the testing machine at a strain rate of $10^{-2}$ at $25^{\circ} \mathrm{C}$ to obtain data on compressive and yielding strength, while Vickers hardness measurements were performed using $100 \mathrm{~g}$ before compressive testing. Figure 6(a) shows the compressive curve and Figure 6(b) the hardness behavior of the bulk solders.

As expected, it was observed the strengthening produce by the presence of the SbSn intermetallic compound. The mechanical properties of the bulk Sn-Bi-Sb solders were higher as the amount of antimony increases, making compressive strength augment from $65 \mathrm{MPa}$ to almost $100 \mathrm{MPa}$ when $6 \mathrm{wt} \% \mathrm{Sb}$ was incorporated to the $\mathrm{Sn}-\mathrm{Bi}$ alloy. Besides, hardness was increased by almost $30 \%$ as the amount of antimony augmented in the alloy. This improvement was a consequence of the detected SbSn



(a)



(b)

Figure 6. (a) Effect of antimony additions on stress-strain curve of Sn-Bi alloy; (b) Effect of antimony additions on hardness of Sn-Bi alloy. intermetallic compound in the microstructure. Therefore, the mechanical properties of the bulk solders suggest that $\mathrm{Sn}-\mathrm{Bi}-\mathrm{Sb}$ solders have higher compressive and yielding strength as the amount of antimony increases, and hardness follows the same trend.

In the absence of differential aeration, the formation of anodic and cathodic areas depends on the ability to ionize. Some metals ionize easily, others with difficulty and consequently anodic and cathodic areas may be produced inside the material, for example by segregation or joining of dissimilar metals. As a consequence of the microstructure observed in Sn-Bi-Sb solder alloys, anodic polarization curves were obtained for each alloy in order to evaluate the effect of $\mathrm{Sb}$ on the solder dissolution rate. These curves, as well as Sn-Bi-Sb alloys cathodic polarization curves and conventional $\mathrm{Sn}-38 \mathrm{~Pb}$ alloy cathodic and anodic behavior, are showed in Figure 7. Cathodic and anodic curves are practically the same for the three studied alloys and they exhibit a passive behavior with a high critical current density. However, the passive area is not stable and current increases again as potential increases too. The tin-lead solder cathodic curve exhibits a smaller current density than the other alloys, while the anodic curve does not show a passivation nose as clearly as the others, although it shows a rupture potential, which exhibit very steep slopes over $1 \mathrm{~mA} / \mathrm{cm}^{2}$.

Table 2 shows the relevant electrochemical parameters obtained from the polarization curves of the studied alloys and compares them against the $\mathrm{Sn}-38 \mathrm{~Pb}$ solder, composition corresponding to the $\mathrm{Sn}-\mathrm{Pb}$ eutectic system composition. $\mathrm{E}_{\text {corr }}$ values of the studied alloys are very similar, and nobler, than the $\mathrm{E}_{\text {corr }}$ exhibited by the $\mathrm{Sn}-38 \mathrm{~Pb}$ solder. A tendency toward more noble potentials is observed when increasing $\mathrm{Sb}$ content, which is an expected result due to the noble oxidation potentials exhibited by

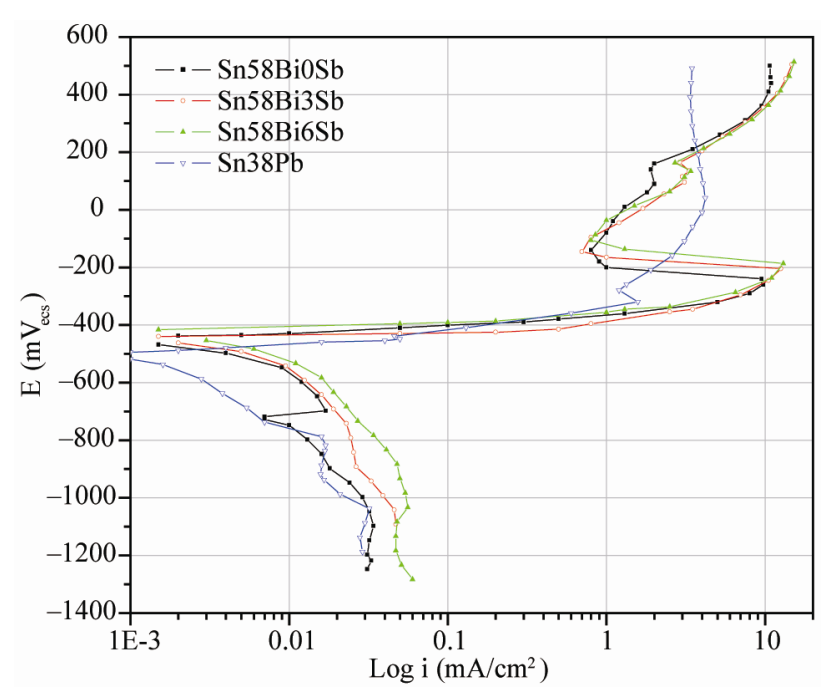

Figure 7. Typical polarization curves of $\mathrm{SnBiSb}$ and $\mathrm{Sn}-38 \mathrm{~Pb}$ alloys in a $3 \% \mathrm{NaCl}$ solution. 
Table 2. Electrochemical parameters obtained from anodic polarization curves.

\begin{tabular}{cccc}
\hline Alloy & $\mathrm{E}_{\text {corr }}\left(\mathrm{mV}_{\text {sce }}\right)$ & $\begin{array}{c}\text { Current Density, } \\
\mathrm{i}_{\text {corr }}\left(\mathrm{mA} / \mathrm{cm}^{2}\right)\end{array}$ & $\begin{array}{c}\text { Passivation Current } \\
\text { Density }\left(\mathrm{mA} / \mathrm{cm}^{2}\right)\end{array}$ \\
\hline $\mathrm{Sn} 38 \mathrm{~Pb}$ & -488 & $6.5 \times 10^{-4}$ & 4.2 \\
$\mathrm{Sn} 58 \mathrm{Bi} 0 \mathrm{Sb}$ & -448 & $1.3 \times 10^{-3}$ & 9.7 \\
$\mathrm{Sn} 58 \mathrm{Bi3Sb}$ & -442 & $1.8 \times 10^{-3}$ & 12.5 \\
$\mathrm{Sn} 58 \mathrm{Bi6Sb}$ & -433 & $2.0 \times 10^{-3}$ & 13.0 \\
\hline
\end{tabular}

this element [18].

The values of the corrosion current density $\left(\mathrm{i}_{\text {corr }}\right)$, determined by the Tafel interpolation method, are quite small and similar, even when the value corresponding to the $\mathrm{Sn}-38 \mathrm{~Pb}$ solder is the smallest. It is observed that increasing $\mathrm{Sb}$ content in the $\mathrm{SnBi}$ alloys slightly increases $i_{\text {corr }}$ and critical current density values. This slight increase in the $i_{\text {corr }}$ value agrees with the statement that the behavior of lead-free solders containing antimony does not differ greatly from that of pure tin [11]. Bi and $\mathrm{Sb}$ are elements that exhibit nobler potentials that $\mathrm{Sn}$ in saline or acid solutions. However, Bi increases the preferential dissolution of $\mathrm{Sn}$ in acid solutions when they are alloyed [8].

\section{Conclusions}

It is clear that both additions into the Sn-Bi eutectic alloy, Sn-Bi-3wt $\% \mathrm{Sb}\left(\mathrm{T}_{\mathrm{m}}=147^{\circ} \mathrm{C}\right)$ and Sn-Bi- $6 \mathrm{wt} \% \mathrm{Sb}\left(\mathrm{T}_{\mathrm{m}}=\right.$ $149^{\circ} \mathrm{C}$ ), are not still far away from the binary eutectic composition $\left(\mathrm{T}_{\mathrm{m}}=139^{\circ} \mathrm{C}\right)$, therefore, liquation or phase separation will not become a potential problem for these solder alloys because $T_{L}-T_{S}<10^{\circ} \mathrm{C}$. In addition, these alloys present a melting temperature that is smaller to the one exhibited by the eutectic alloy $\mathrm{Sn}-38 \mathrm{~Pb}\left(\mathrm{~T}_{\mathrm{m}}=183^{\circ} \mathrm{C}\right)$. Moreover, the low melting temperatures of this solder alloys may permit to add more elements to further improve their properties in future works.

The mechanical properties of the bulk $\mathrm{Sn}-\mathrm{Bi}-\mathrm{Sb}$ solders were higher as the amount of antimony increases, making compressive strength increase from $65 \mathrm{MPa}$ to almost $100 \mathrm{MPa}$ when $6 \mathrm{wt} \% \mathrm{Sb}$ was incorporated to the Sn-Bi alloy. Besides, hardness followed the same trend. This improvement was a consequence of the observed $\mathrm{SbSn}$ intermetallic compound in the microstructure leading to a strengthening effect.

According to these first reported electrochemical results, the addition of higher contents of $\mathrm{Sb}$ to the $\mathrm{Sn}-\mathrm{Bi}$ eutectic alloy had opposite effects: on one hand it ennobled the $\mathrm{E}_{\text {corr }}$ values and on the other hand it lightly increased the $i_{\text {corr }}$ values that are proportional to corrosion rate. Although the three studied alloys exhibited passive behavior in the solution of $\mathrm{NaCl}$, their critical current density was high and the potential interval for passivity was narrow producing once again a current increase as potential was raised.

\section{REFERENCES}

[1] K. Suganuma and K. Kim, "Sn-Zn Low Temperature Solders," Journal of Materials Science: Materials for Electronics, Vol. 18, No. 1-3, 2007, pp. 121-127. doi:10.1007/s10854-006-9018-2

[2] K. N. Subramanian and J. G. Lee, "Physical Metallurgy in Lead-Free Electronic Solder Development," JOM Journal of the Minerals, Metals and Materials Society, Vol. 55, No. 5, 2003, pp. 26-32. doi:10.1007/s11837-003-0242-4

[3] J. Glazer, "Metallurgy of Low Temperature Pb-Free Solders for Electronic Assembly," International Materials Review, Vol. 40, No. 2, 1995, pp. 65-93. doi:10.1179/095066095790151115

[4] L. Duan, D. Q. Yu, S. Q. Han, H. T. Ma and L. Wang, "Microstructural Evolution of Sn-9Zn-3Bi Solder/Cu Joint during Long-Term Aging at $170^{\circ} \mathrm{C}$," Journal of $\mathrm{Al}$ loys and Compounds, Vol. 381, No. 1-2, 2004, pp. 202207. doi:10.1016/j.jallcom.2004.03.124

[5] C. W. Hwang and K. Suganuma, "Joint Reliability and High Temperature Stability of Sn-Ag-Bi Lead-Free Solder with $\mathrm{Cu}$ and $\mathrm{Sn}-\mathrm{Pb} / \mathrm{Ni} / \mathrm{Cu}$ Substrates," Materials Science and Engineering, Vol. 373, No. 1-2, 2004, pp. 187 194. doi:10.1016/j.msea.2004.01.019

[6] H. L. Lai and J. G. Duh, "Lead-Free Sn-Ag and Sn-Ag-Bi Solder Powders Prepared by Mechanical Alloying," Journal of Electronic Materials, Vol. 32, No. 4, 2003, pp. 215-220. doi:10.1007/s11664-003-0212-1

[7] H. W. Miao and J. G. Duh, "Microstructural Evolution in $\mathrm{Sn}-\mathrm{Bi}$ and $\mathrm{Sn}-\mathrm{Bi}-\mathrm{Cu}$ Solder Joints under Thermal Aging," Materials Chemistry and Physics, Vol. 71, No. 3, 2001, pp. 255-271. doi:10.1016/S0254-0584(01)00298-X

[8] M. Mori, K. Miura, T. Sasaki and T. Ohtsuka, "The Corrosion of Tin Alloys in Sulfuric and Nitric Acids," Corrosion Science, Vol. 44, No. 4, 2002, pp. 887-898. doi:10.1016/S0010-938X(01)00094-4

[9] W. R. Osorio, L. R. Garcia, L. C. Peixoto and A. Garcia, "Electrochemical Behavior of Lead-Free Snag Solder Alloy Affected by the Microstructure," Materials and Design, Vol. 32, No. 10, 2011, pp. 4763-4772. doi:10.1016/j.matdes.2011.06.032

[10] D. Li, P. P. Conway and C. Liu, "Corrosion Characterization of Tin-Lead and Lead-Free Solders in $3.5 \mathrm{wt} \% \mathrm{NaCl}$ Solution," Corrosion Science, Vol. 50, No. 4, 2008, pp. 995-1004. doi:10.1016/j.corsci.2007.11.025

[11] M. Dighe, "Corrosion of Materials," ASM International, Materials Park, 2005.

[12] H. Okamoto, "Desk Handbook: Phase Diagrams for Binary Alloys," 2nd Edition, ASM International, Materials Park, 2010.

[13] J. D. Verhoeven, "Fundamentals of Physical Metallurgy," John Wiley \& Sons, New York, 1989.

[14] J. A. Dantzing and M. Rappaz, "Solidification," CRC Press, London, 2009. 
[15] R. W. Cahn and P. Haasen, "Physical Metallurgy," 4th Edition, North-Holland Publishing Company, Amsterdam, 1996.

[16] W. Kurz and D. J. Fisher, "Fundamentals of Solidification," 4th Edition, Trans Tech Publications, Zurich, 1998.
[17] G. Humpston and D. M. Jacobson, "Principles of Soldering and Brazing," ASM International, Materials Park, 1993.

[18] R. Chang and J. Overby, "General Chemistry," 6th Edition, McGraw-Hill, New York, 2010. 